\title{
Effect of an herbal formulation on DOCA-salt and fructose induced models of hypertension in rats
}

\author{
CL Athare, M Mohan* and SB Kasture \\ Department of Pharmacology, M. G. V's Pharmacy College, Panchavati, Nasik, Maharashtra 422 003, India
}

Received for publication August 16, 2007; accepted January 07, 2008

\begin{abstract}
SUMMARY
The present study was carried out to investigate the antihypertensive effect of a folklore herbal formulation (HF) $(300 \mathrm{mg} / \mathrm{kg} /$ day; p.o.) in deoxycorticosterone acetate (DOCA)-salt induced and fructose induced hypertensive rats. In DOCA model, DOCA (15 mg/ kg, s.c., twice a week) was administered to unilateral nephrectomized rats for 4 weeks. In fructose model, drinking water was replaced with $10 \%$ fructose solution for 6 weeks to induce hypertension. Systolic blood pressure (BP) was measured once every week during the treatment schedule. After completion of treatment schedule, BP and vascular reactivity to various agonists like Noradrenaline, Adrenaline, Phenylephrine and Serotonin (5-hydroxytrptamine; 5-HT) were recorded in rats of both models. A cumulative concentration response curve of 5-HT was carried out in isolated rat fundus strip of the DOCA-salt induced and fructose induced hypertensive rats. The results tend to suggest that HF possesses antihypertensive activity.
\end{abstract}

Key words: Deoxycorticosterone acetate; Fructose; 5-hydroxytrptamine; Hypertension.

\section{INTRODUCTION}

Hypertension is the most common cardiovascular disease and is a major public health issue in developed as well as developing countries. Although it is common and readily detectable, it can often lead to lethal complications if left untreated. Various classes of drugs and regimens have been advocated for the control of hypertension because of its high incidence and morbidity. Despite the large armamentaria of drugs being available for the treatment of hypertension, the last two decades have witnessed

\footnotetext{
${ }^{*}$ Correspondence: M Mohan, Department of Pharmacology, M. G. V's Pharmacy College, Panchavati, Nashik, Maharashtra, 422003, India. Tel: +9823234514; Fax: +0253-2511931; E-mail: mm_nasik@yahoo.co.in
}

the introduction of a number of new antihypertensive drugs (Badyal et al., 2003). It has been hypothesized that $5 \mathrm{HT}_{2 \mathrm{~B}}$ receptor is upregulated and necessary for maintaining elevated blood pressure (BP) in rats made hypertensive by deoxycorticosterone acetate (DOCA) and N-nitro-L-arginine methyl ester (NAME) (Banes and Watts, 2003). High fructose or high sucrose diets have been documented to increase BP in experimental rats (Bunnag et al., 1997; Cosenzi et al., 1999). Numerous drugs from plants have also been used in the treatment of hypertension. Solanum sisymbriifolium (Ibarrol et al., 1996), Spergularia purpurea (Jouad et al., 2001), Croton schiedeanus (Guerrero et al., 2001), Bidens pilosa (Dimo et al., 2001), Stephaniae tetrandrae (RAO, 2002), Trigonella Foenum-greacum (Balaraman et al., 2006) are some of the plants used in hypertension. 
In the traditional system of medicine, herbs have been used in combination. Drug combination ensures synergism and helps to overcome the side effects of each other (Shah et al., 1997). The enormous amount spent on herbs clearly suggests the importance of herbs in pharmacotherapy (Sharma, 2004). The folklore herbal formulation (HF) consists of Glycyrrhiza glabra, Nelumbo nucifera, Zingiber officinale, Eclipta alba, Hibiscus rosasinensis, Hemidesmus indicus, Rosa damascena, Quercus infectoria and Terminalia chebula. Some of these ingredients have been proved to have beneficial effects on cardiovascular system (Inamadar and Rajarama, 1962; Mishra et al., 1999; Gupta et al., 1976). The present study is aimed to evaluate whether a folklore HF is effective in preventing DOCA-salt and fructose induced hypertension in rats.

\section{MATERIALS AND METHODS}

\section{Animals}

Wistar rats of either sex (150 - $200 \mathrm{~g})$ were obtained from Serum Institute, Pune. Animals were housed into groups of five at an ambient temperature of 25 $\pm 1^{\circ} \mathrm{C}$. Animals had free access to food and water. They were then trained for a week to become accustomed to the procedure of indirect BP measurement. The Institutional Animal Ethical Committee (IAEC) approved the protocol of this study.

\section{Drugs and chemicals}

Noradrenaline (NA), Adrenaline (Adr), Phenylephrine (PE), 5-HT, DOCA and urethane were purchased from Sigma (USA). Fructose was obtained from Merck (India). DOCA was dispersed in cottonseed oil. Urethane and fructose solutions were prepared in distilled water. HF ( $300 \mathrm{mg} / \mathrm{kg} /$ day p.o.) was prepared in distilled water and administered orally. All drug solutions were prepared in normal saline. $1 \% \mathrm{NaCl}$ and $0.2 \% \mathrm{KCl}$ were freshly prepared in distilled water.

\section{Induction of hypertension DOCA-salt induced hypertension}

Hypertension was induced experimentally in female rats (150 - $200 \mathrm{~g}$ ) by unilateral nephrectomy (Nakagawa and Nasjletti, 1988). Rats were anaesthetized with diethyl ether and a lateral incision was made in the area overlapping the kidney. The kidney was pulled up and the artery was tied with thread. It was then removed with scissor. The incision was sutured and closed with Michel clips. All operated rats received an injection of ampicillin $(10 \mathrm{mg} / \mathrm{kg}$, i.m.) daily for 5 days. Neosporin powder (GlaxoSmithKline) was applied locally to prevent infection. A week later, DOCA $(15 \mathrm{mg} / \mathrm{kg}$, twice a week; s.c. for 4 weeks) dispersed in cottonseed oil was injected to unilaterally nephrectomized rats. A solution of $1 \%$ saline $+0.2 \%$ $\mathrm{KCl}$ was given ad libitum as drinking water.

\section{Fructose induced hypertension}

Hypertension was induced experimentally in male Wistar rats $(150-200 \mathrm{~g})$ by high fructose diet (Fructose 10\% w/v) ad libitum for 6 weeks. Fructose solution was prepared every 2 days by dissolving the fructose in distilled water (Vogel, 2002).

\section{Experimental protocol \\ DOCA-salt induced hypertension model}

A total of 20 unilateral nephrectomized female Wistar rats (150 - $200 \mathrm{~g})$ were randomized into four groups of five animals each.

Group I: Sham control: Sham operated control animals received daily injection of $0.1 \mathrm{ml}$ of sterilized cottonseed oil subcutaneously and $1 \%$ saline $+0.2 \% \mathrm{KCl}$ ad libitum as drinking water for 4 weeks.

Group II: DOCA: Unilateral nephrectomized animals received DOCA injection $(15 \mathrm{mg} / \mathrm{kg}$, s.c., twice a week) dispersed in cotton seed oil and 1\% saline $+0.2 \% \mathrm{KCl}$ ad libitum as drinking water for 4 weeks.

Group III: DOCA + HF: Unilateral nephrectomized animals received DOCA injection $(15 \mathrm{mg} / \mathrm{kg}$, s.c., 
twice a week), herbal formulation $(300 \mathrm{mg} / \mathrm{kg} /$ day, p.o.) and $1 \%$ saline $+0.2 \% \mathrm{KCl}$ ad libitum as drinking water for 4 weeks.

Group IV: HF: Unilateral nephrectomized animals received herbal formulation $(300 \mathrm{mg} / \mathrm{kg} /$ day, p.o.) and $1 \%$ saline $+0.2 \% \mathrm{KCl}$ ad libitum as drinking water for 4 weeks.

\section{Fructose-induced hypertension model}

A total of 24 male Wistar rats $(150-200 \mathrm{~g})$ were randomized and divided into four groups of six each.

Group I: Control: Animals received no medication but were given distilled water for drinking.

Group II: Fructose 10\%: Animals received 10\% fructose solution instead of drinking water ad libitum for 6 weeks.

Group III: Fructose 10\% + HF: Animals received $10 \%$ fructose solution instead of drinking water ad libitum with HF ( $300 \mathrm{mg} / \mathrm{kg} /$ day, p.o.) for 6 weeks. Group IV: HF: Animals received HF $(300 \mathrm{mg} / \mathrm{kg} /$ day, p.o.) and distilled water for drinking for 6 weeks.

\section{Measurement of BP}

Measurement of BP by noninvasive (indirect) method For arterial BP measurement using tail cuff method, rats were trained for at least one week until the BP was steadily recorded with minimal stress and restrain. The first cardiovascular parameters were discarded and mean of five or six subsequent measurements were recorded. Systolic BP was measured weekly for 4 weeks by indirect noninvasive tail-cuff method using PowerLab/4sp (ADInstrument, Australia).

\section{Measurement of BP by invasive (direct) method}

After completion of the treatment schedule, rats from each group were anesthetized with urethane $(120 \mathrm{mg} / 100 \mathrm{~g})$. Femoral vein was cannulated with fine polyethylene catheter for administration of the drug. Tracheostomy was performed and BP was recorded from left common carotid artery using pressure transducer by direct method on Chart data system. Heparinised saline $(250 \mathrm{IU} / \mathrm{ml})$ was filled in the transducer and in the fine polyethylene catheter cannulated to the carotid artery to prevent clotting. After $30 \mathrm{~min}$ of stabilization, BP and vascular reactivity to NA ( $2 \mu \mathrm{g} / \mathrm{kg})$, Adr $(2 \mu \mathrm{g} / \mathrm{kg})$, PE $(2 \mu \mathrm{g} / \mathrm{kg})$ and 5-HT $(2 \mu \mathrm{g} / \mathrm{kg})$ were recorded.

\section{In vitro studies}

After completion of treatment schedule in the DOCA-salt induced and fructose inducedhypertensive groups, individual rat were sacrificed. The fundus was removed and placed in Krebs solution. The physiological salt solution had the following composition (mM): $\mathrm{NaCl},(118) ; \mathrm{KCl}$, (4.7); $\mathrm{CaCl}_{2}$, (2.5); $\mathrm{MgSO}_{4},(1.2) ; \mathrm{NaHCO}_{3,}$ (25); $\mathrm{KH}_{2} \mathrm{PO}_{4},(1.2)$; and Glucose, (11). The physiological salt solution had a $\mathrm{pH}$ of 7.4. It was warmed to 37C and aerated with $95 \% \mathrm{O}_{2}$ and $5 \% \mathrm{CO}_{2}$ (Carbogen). One end was tied to an aerator tube and the other end to the frontal writing lever. Each strip was placed under optimum resting tension $(1.5 \mathrm{~g})$ and allowed to equilibrate for $30 \mathrm{~min}$ with frequent changes of Krebs solution at $10 \mathrm{~min}$ interval. Cumulative concentration response curve (CCRC) of 5-HT was recorded for $90 \mathrm{~s}$ for each tissue preparation on Sherington's recording drum.

\section{Statistics}

The mean \pm S.E.M. values were calculated for each group. One-way ANOVA followed by Dunnett's multiple comparison tests were used for statistical analysis. Values of $p<0.05$ were considered statistically significant.

\section{RESULTS}

Antihypertensive effect of $\mathrm{HF}(300 \mathrm{mg} / \mathrm{kg})$ on DOCA-salt induced hypertensive rats Measurement of BP by noninvasive (indirect) method

The systolic BP in sham control rats was observed in a close range. Administration of DOCA significantly 


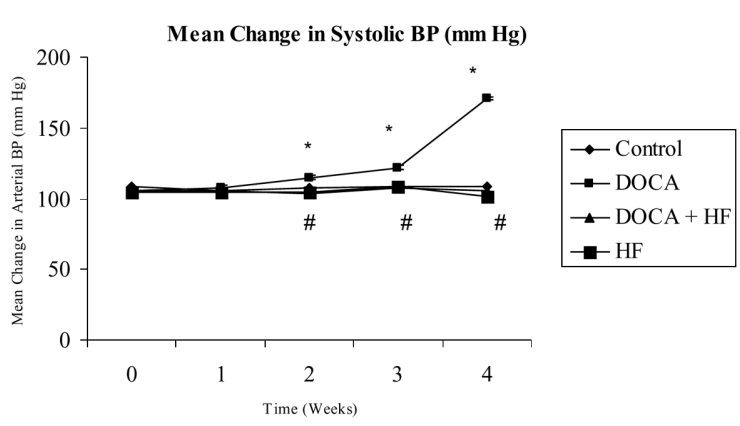

Fig. 1. Time course (weekly) changes in mean SBP $(\mathrm{mmHg})$ during 4 weeks in sham control, DOCA, DOCA + HF (300 mg/kg) and HF (300 mg/kg) treated groups. The observations are mean \pm S.E.M. (ANOVA followed by Dunnett's test). ${ }^{*} P<0.05$ as compared with control group. ${ }^{\#} P<0.05$ as compared with DOCA hypertensive rats. Vertical lines represent S.E.M. $\mathrm{n}=5$. HF- Herbal formulation.

increased SBP from $106.7 \pm 1.27 \mathrm{mmHg}$ to $175 \pm$ $3.17 \mathrm{mmHg}$. HF when administered with DOCA, significantly $(p<0.05)$ reversed the hypertensive effects of DOCA. HF did not exhibit any significant change in systolic BP. Administration of HF (300 $\mathrm{mg} / \mathrm{kg} /$ day, p.o.) for 4 weeks in DOCA-salt induced unilateral nephrectomised hypertensive rats significantly reduced the systolic $\mathrm{BP}$ as compared with DOCA-salt induced hypertensive rats alone, implying an antihypertensive effect of HF (Fig. 1).

Measurement of BP by invasive (direct) method Administration of DOCA for 4 weeks in unilateral nephrectomized rats produced a significant elevation $(p<0.05)$ in mean arterial BP (MABP) $(130.66 \pm$ $10.84 \mathrm{mmHg}$ ) as compared to sham control rats $(99.00 \pm 4.00 \mathrm{mmHg})$. Chronic administration of $\mathrm{HF}$ (300 mg/ kg/day, p.o.) for 4 weeks did not alter $\mathrm{BP}$ as compared to sham control. However, chronic administration of $\mathrm{HF}$ ( $300 \mathrm{mg} / \mathrm{kg} /$ day, p.o.) for 4 weeks, in unilateral nephrectomized DOCA-salt treated hypertensive rats significantly $(p<0.05)$ reduced mean arterial BP $(92.33 \pm 5.78 \mathrm{mmHg})$ as compared with MABP $(130.66 \pm 10.84 \mathrm{mmHg})$ of DOCA-salt hypertensive rats implying an antihypertensive effect (Fig. 2a).
Effect of HF ( $300 \mathrm{mg} / \mathrm{kg} /$ day, p.o.) for 4 weeks on vascular reactivity to NA, Adr, PE and 5-HT in DOCA-salt hypertensive rats

Presssor responses to NA, Adr, PE and 5-HT were not altered in case of HF $(300 \mathrm{mg} / \mathrm{kg} /$ day, p.o.) treated rats as compared with sham control rats. Pressor responses to NA, Adr, PE and 5-HT were significantly $(p<0.05)$ increased in case of unilateral nephrectomized DOCA-salt treated hypertensive rats as compared with sham control rats. Pressor responses to 5 -HT were significantly $(p<0.05)$ reduced in case of unilateral nephrectomized DOCA-salt treated rats that received $\mathrm{HF}(300 \mathrm{mg} / \mathrm{kg} /$ day, p.o.) for 4 weeks as compared with DOCA-salt treated hypertensive rats (Fig. 2b- Fig. 2e).

Effect of HF (300 mg/kg/day, p.o.) for 4 weeks on cumulative concentration response curve on isolated rat stomach fundus strip in DOCA-salt induced hypertensive rats

Chronic administration of HF $(300 \mathrm{mg} / \mathrm{kg})$ for 4 weeks in DOCA-salt induced hypertensive rats significantly $(p<0.05)$ shifted the cumulative concentration response curve of 5-HT to the right with suppression of maxima as compared to cumulative concentration response curve of DOCAsalt induced hypertensive rats on isolated stomach fundus strip (Fig. 5).

Antihypertensive effect of HF (300 $\mathrm{mg} / \mathrm{kg})$ on fructose induced hypertensive rats

Measurement of BP by noninvasive (indirect) method

The systolic BP in vehicle treated rats was observed in a close range. Administration of fructose significantly increased SBP from $108 \pm 1.03 \mathrm{mmHg}$ to $179 \pm 2.59$ mmHg. The HF ( $300 \mathrm{mg} / \mathrm{kg}$, p.o.) when administered with fructose significantly reversed the hypertensive effect of fructose. HF did not exhibit any significant change in systolic BP. Administration of HF (300 $\mathrm{mg} / \mathrm{kg} /$ day, p.o.) for 6 weeks in fructose-induced hypertension in rats significantly $(p<0.05)$ reduced the systolic BP as compared with fructose induced 

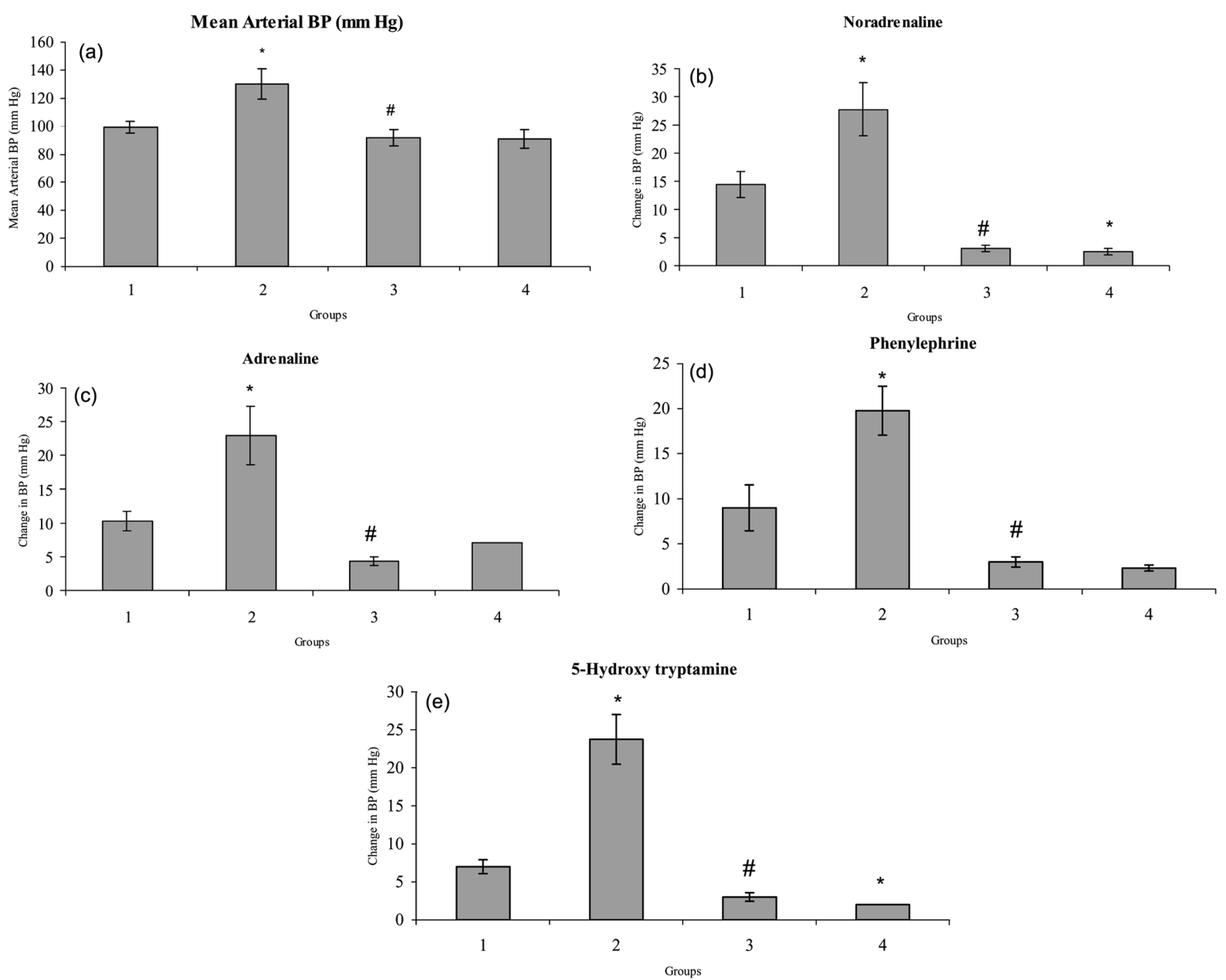

Fig. 2. (a) MABP (mmHg) after completion of treatment schedule in (1) Sham control, (2) DOCA, (3) DOCA + HF $(300 \mathrm{mg} / \mathrm{kg})$ and $(4) \mathrm{HF}(300 \mathrm{mg} / \mathrm{kg}$ ) treated groups. The observations are mean \pm S.E.M. (ANOVA followed by Dunnett's test). ${ }^{*} P<0.05$ as compared with control group. ${ }^{\#} P<0.05$ as compared with DOCA hypertensive rats. Vertical lines represent S.E.M. $n=5$. HF- Herbal formulation. (b) Mean change in BP to Noradrenaline in (1) sham control, (2) DOCA, (3) DOCA + HF (300 mg/kg) and (4) HF (300 mg/ kg) treated groups. The observations are mean \pm S.E.M. (ANOVA followed by Dunnett's test). ${ }^{*} P<0.05$ as compared with control group. ${ }^{\#} P<0.05$ as compared with DOCA hypertensive rats. Vertical lines represent S.E.M. $n=5$. HF- Herbal formulation. (c) Mean change in BP to Adrenaline in (1) Sham control, (2) DOCA, (3) DOCA + HF (300 mg/kg) and (4) HF (300 mg/kg) treated groups. The observations are mean \pm S.E.M. (ANOVA followed by Dunnett's test). ${ }^{*}<0.05$ as compared with control group. ${ }^{\#}<0.05$ as compared with DOCA hypertensive rats. Vertical lines represent S.E.M. $n=5$. HF- Herbal formulation. (d) Mean change in BP to Phenylephrine in (1) Sham control, (2) DOCA, (3) DOCA + HF $(300 \mathrm{mg} / \mathrm{kg})$ and $(4) \mathrm{HF}(300 \mathrm{mg} / \mathrm{kg})$ treated groups. ${ }^{*} P<0.05$ as compared with control group. ${ }^{\#} P<0.05$ as compared with DOCA hypertensive rats. Vertical lines represent S.E.M. $\mathrm{n}=5$. (e) Mean change in BP to 5-Hydroxy tryptamine in (1) Sham control, (2) DOCA, (3) DOCA + HF (300 mg/ kg) and (4) HF (300 mg/kg) treated groups. The observations are mean \pm S.E.M. (ANOVA followed by Dunnett's test). ${ }^{*} P<0.05$ as compared with control group. ${ }^{\#} P<0.05$ as compared with DOCA hypertensive rats. Vertical lines represent S.E.M. $\mathrm{n}=5$. HF- Herbal formulation.

hypertensive rats alone, implying an antihypertensive effect of HF (Fig. 3).
Measurement of BP by invasive (direct) method

Fructose treatment for 6 weeks in normal rats 


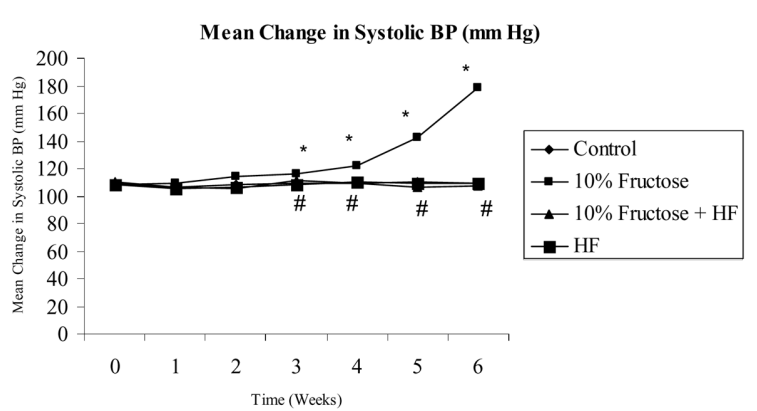

Fig. 3. Time course (weekly) changes in mean systolic $\mathrm{BP}(\mathrm{mmHg})$ during 6 weeks in control, $10 \%$ fructose, $10 \%$ fructose $+\mathrm{HF}(300 \mathrm{mg} / \mathrm{kg})$ and $\mathrm{HF}(300 \mathrm{mg} / \mathrm{kg})$ treated groups. The observations are mean \pm S.E.M. (ANOVA followed by Dunnett's test). ${ }^{*}<0.05$ as compared with control group. ${ }^{\#} P<0.05$ as compared with Fructose hypertensive rats. Vertical lines represent S.E.M. $\mathrm{n}=5$. HF- Herbal formulation.

produced a significant elevation $(p<0.05)$ means arterial BP (131 $\pm 5.11 \mathrm{mmHg})$ as compared to control rats $(99 \pm 4.00 \mathrm{mmHg})$. Chronic administration of $\mathrm{HF}(300 \mathrm{mg} / \mathrm{kg} /$ day, p.o.) for 6 weeks did not alter BP as compared to control. However, chronic administration of $\mathrm{HF}$ (300 mg/ $\mathrm{kg} /$ day, p.o.) for 6 weeks in fructose-induced hypertensive rats significantly $(p<0.05)$ reduced mean arterial BP $(106 \pm 3.42 \mathrm{mmHg})$ as compared with mean arterial BP $(131 \pm 5.11 \mathrm{mmHg})$ of fructose-induced hypertensive rats implying an antihypertensive effect (Fig. 4a).

Effect of HF ( $300 \mathrm{mg} / \mathrm{kg} /$ day, p.o.) for 6 weeks on vascular reactivity to NA, Adr, PE and 5-HT in fructose induced hypertensive rats

Presssor responses to NA, Adr, PE and 5-HT were not altered in case of $\mathrm{HF}(300 \mathrm{mg} / \mathrm{kg} /$ day, p.o. $)$ treated rats as compared with control rats. Pressor responses to NA, Adr, $\mathrm{PE}$ and 5-HT were significantly $(p<0.05)$ increased in case of fructose induced hypertensive rats as compared with control rats. Pressor responses to 5-HT were significantly $(p<0.05)$ reduced in case of fructose induced hypertensive rats that received HF (300 $\mathrm{mg} / \mathrm{kg} /$ day, p.o.) for 6 weeks as compared with fructose induced hypertensive rats (Fig. $4 \mathrm{~b}-4 \mathrm{e}$ ).
Effect of HF (300 mg/kg/day, p.o.) for 6 weeks on cumulative concentration response curve on isolated rat stomach fundus strip in fructose induced hypertensive rats

Chronic administration of HF $(300 \mathrm{mg} / \mathrm{kg})$ for 6 weeks in fructose induced hypertensive rats significantly $(p<0.05)$ shifted the cumulative concentration response curve of 5-HT to the right with suppression of maxima as compared to cumulative concentration response curve of fructose induced hypertensive rats on isolated stomach fundus strip (Fig. 6).

\section{DISCUSSION}

The aim of the present study was to investigate the antihypertensive property of a folklore herbal formulation in DOCA-salt induced and fructose induced hypertensive rats. The study showed that chronic administration of HF $(300 \mathrm{mg} / \mathrm{kg} /$ day, p.o.) for 4 weeks significantly reduced $\mathrm{BP}$ of unilateral nephrectomized DOCA-salt hypertensive rats. Chronic administration of $\mathrm{HF}(300 \mathrm{mg} / \mathrm{kg} /$ day, p.o.) for 6 weeks significantly reduced BP in fructose induced hypertensive rats. However SBP and MABP did not alter in normotensive rats in both models. This shows that HF ( $300 \mathrm{mg} / \mathrm{kg} /$ day, p.o.) possess antihypertensive property. Female rats were used in the DOCA-salt hypertensive model as they appear to be more susceptible to development of hypertension (Greenberg et al., 1973; Balaraman et al., 1989).

Most of the ingredients of HF are known to have beneficial effects on the heart. T. chebula has been reported to act directly on the heart muscle. The negative chronotropic, inotropic and hypotensive responses observed with it might protect the myocardium by decreasing its overload (Srivastava $e t$ al., 1991). N. nucifera (Chopra et al., 1969) and Z. officinale (Bone and Gupta, 1997) are being recommended as cardiotonic in traditional medicines and have been scientifically proved. T. chebula (Inamadar and Rajarama 1962), H. rosasinensis (Mishra et al., 1999) 

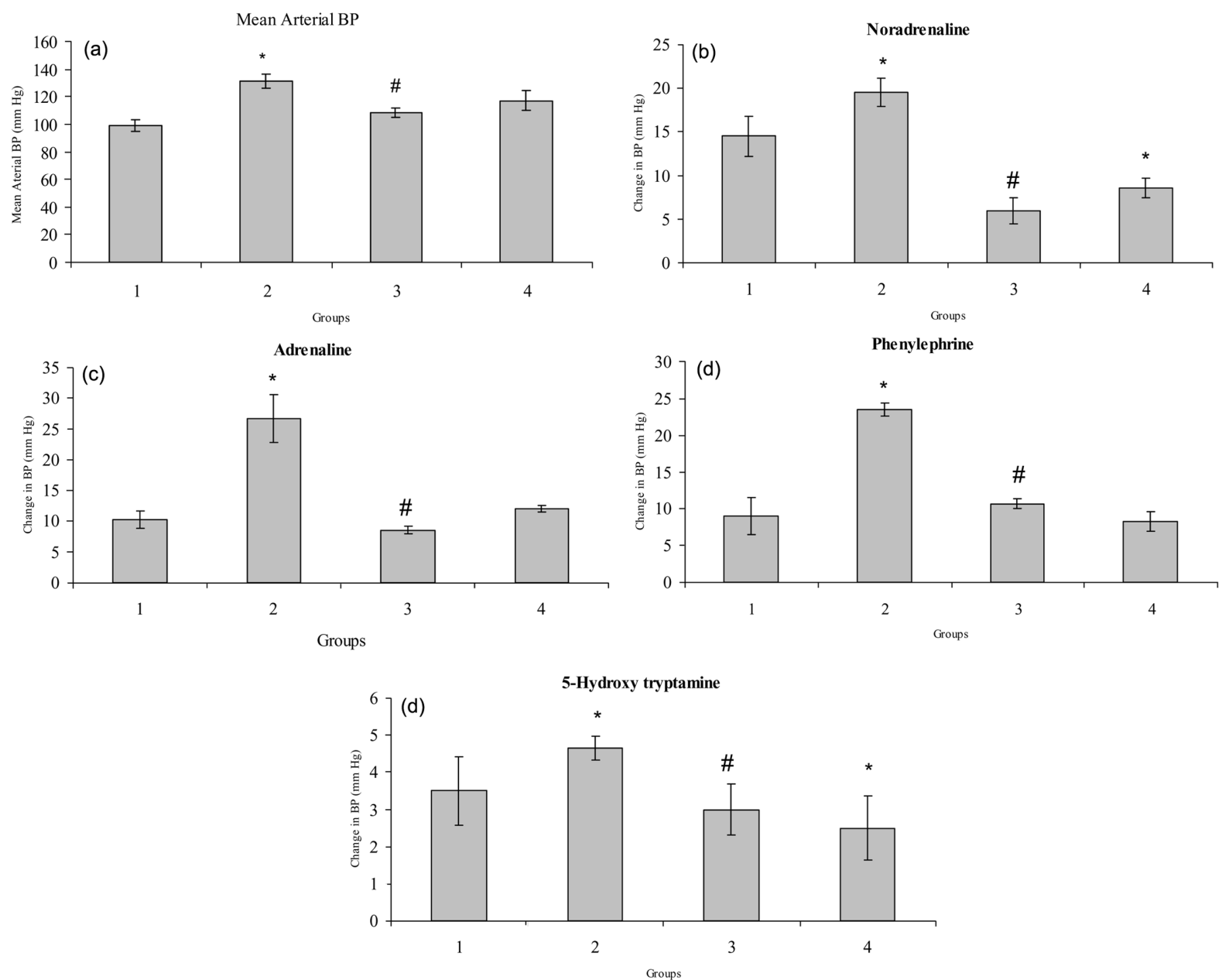

Fig. 4. (a) MABP (mmHg) after completion of treatment schedule in (1) control, (2) $10 \%$ fructose, (3) $10 \%$ fructose $+\mathrm{HF}(300 \mathrm{mg} / \mathrm{kg})$ and $(4) \mathrm{HF}(300 \mathrm{mg} / \mathrm{kg})$ treated groups. The observations are mean \pm S.E.M. (ANOVA followed by Dunnett's test). ${ }^{*} P<0.05$ as compared with control group. ${ }^{\#} P<0.05$ as compared with Fructose hypertensive rats. Vertical lines represent S.E.M. $n=5$. HF- Herbal formulation. (b) Mean change in BP to Noradrenaline in (1) control, (2) $10 \%$ fructose, (3) $10 \%$ fructose + HF (300 mg/kg) and (4) HF (300 mg/ $\mathrm{kg}$ ) treated groups. The observations are mean \pm S.E.M. (ANOVA followed by Dunnett's test). ${ }^{*} P<0.05$ as compared with control group. ${ }^{\#} P<0.05$ as compared with Fructose hypertensive rats. Vertical lines represent S.E.M. $\mathrm{n}=5$. HFHerbal formulation. (c) Mean change in BP to Adrenaline in (1) control, (2) $10 \%$ fructose, (3) $10 \%$ fructose + HF $(300 \mathrm{mg} / \mathrm{kg})$ and $(4) \mathrm{HF}(300 \mathrm{mg} / \mathrm{kg})$ treated groups. The observations are mean \pm S.E.M. (ANOVA followed by Dunnett's test). ${ }^{*} P<0.05$ as compared with control group. ${ }^{\#} P<0.05$ as compared with Fructose hypertensive rats. Vertical lines represent S.E.M. $n=5$. HF- Herbal formulation. (d) Mean change in BP to Phenylephrine in (1) control, (2) $10 \%$ fructose, (3) $10 \%$ fructose $+\mathrm{HF}(300 \mathrm{mg} / \mathrm{kg}$ ) and (4) $\mathrm{HF}(300 \mathrm{mg} / \mathrm{kg})$ treated groups. The observations are mean \pm S.E.M. (ANOVA followed by Dunnett's test). ${ }^{*} P<0.05$ as compared with control group. ${ }^{\#} P<0.05$ as compared with Fructose hypertensive rats. Vertical lines represent S.E.M. $n=5$. HF-Herbal formulation. (e) Mean change in BP to 5-Hydroxy tryptamine in (1) control, (2) $10 \%$ fructose, (3) $10 \%$ fructose + $\mathrm{HF}(300 \mathrm{mg} / \mathrm{kg})$ and $(4) \mathrm{HF}(300 \mathrm{mg} / \mathrm{kg})$ treated groups. The observations are mean \pm S.E.M. (ANOVA followed by Dunnett's test). ${ }^{*} P<0.05$ as compared with control group. ${ }^{*} P<0.05$ as compared with Fructose hypertensive rats. Vertical lines represent S.E.M. $n=5$. HF- Herbal formulation.

and E. alba (Gupta et al., 1976) have been proved to have beneficial effects on cardiovascular system.
The free radical scavenging properties of G. glabra (Takagi and Sanashiro 1996; Alam and Gomes 


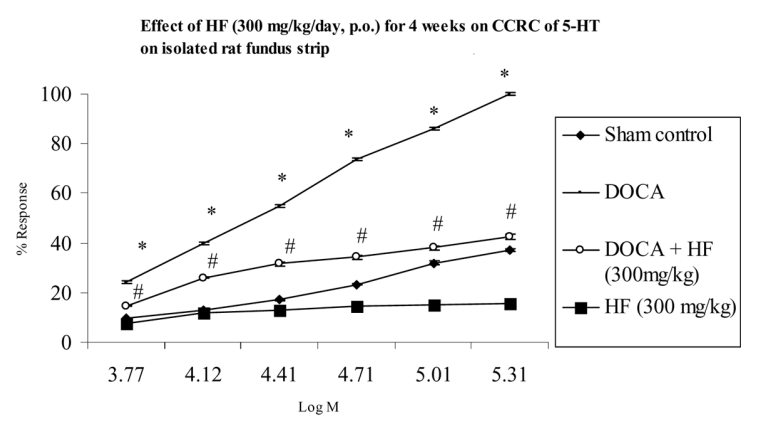

Fig. 5. Effect of HF (300 mg/kg/ day, p.o., for 4 weeks) on CCRC of 5-HT on isolated rat fundus strip in sham control, DOCA, DOCA + HF, and HF treated groups. ${ }^{*} P<0.05$ as compared with sham control group. ${ }^{\#} P<$ 0.05 as compared with DOCA hypertensive rats. Vertical lines represent S.E.M. $\mathrm{n}=5$.

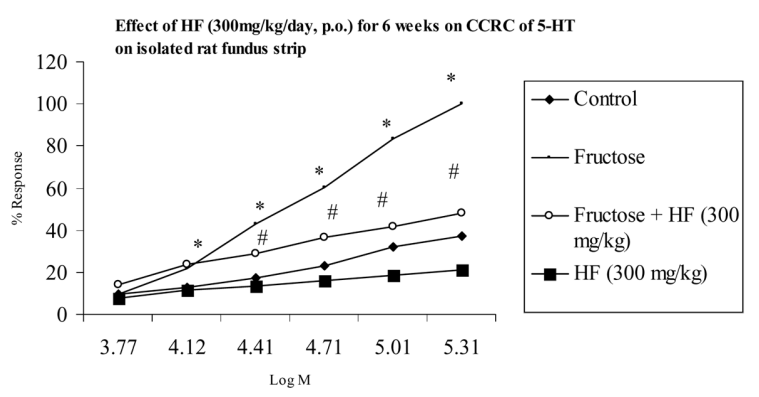

Fig. 6. Effect of HF (300 mg/kgday, p.o.) for 6 weeks on CCRC of 5 -HT on isolated rat fundus strip in control, $10 \%$ fructose, $10 \%$ fructose $+\mathrm{HF}(300 \mathrm{mg} / \mathrm{kg})$ and HF $(300 \mathrm{mg} / \mathrm{kg})$ treated groups. ${ }^{*} P<0.05$ as compared with control group. ${ }^{\#}<0.05$ as compared with Fructose hypertensive rats. Vertical lines represent S.E.M. $\mathrm{n}=5$.

1998), T. chebula (Aeshbaech et al., 1994), H. indicus (Chandra et al., 1987), Z. officinale (Sreeramamurthy et al., 1993) and E. alba (Kim and Hong, 1996) might synergistically enhance the antihypertensive efficacy of folklore HF.

There was an increase in SBP in DOCA-salt treated hypertensive rats at $4^{\text {th }}$ week and fructose induced hypertensive rats at $6^{\text {th }}$ week as measured by NIBP. HF did not exhibit any significant change in SBP. Administration of HF $(300 \mathrm{mg} / \mathrm{kg} /$ day, p.o.) for 4 weeks in DOCA-salt induced hypertension in unilateral nephrectomized rats and in fructose induced hypertensive rats significantly $(p<0.05)$ reduced the systolic $\mathrm{BP}$ as compared to respective controls.

Vascular reactivity to NA ( $2 \mu \mathrm{g} / \mathrm{kg}), \operatorname{Adr}(2 \mu \mathrm{g} / \mathrm{kg})$, $\mathrm{PE}(2 \mu \mathrm{g} / \mathrm{kg})$ and 5-HT $(2 \mu \mathrm{g} / \mathrm{kg})$ was measured by IBP technique in DOCA-salt treated hypertensive rats and fructose hypertensive rats. As described earlier by Balaraman et al., (1993) reduction in vascular reactivity to various agonists by $\mathrm{HF}(300$ $\mathrm{mg} / \mathrm{kg} /$, p.o., per day) in DOCA-salt treated hypertensive rats and fructose hypertensive rats suggests that there is alteration in the sensitivity of the adrenoceptors to NA, Adr, PE and 5-HT.

At the end of the treatment schedule rats from both models were sacrificed and fundus strip was removed for recording the CCRC of 5-HT. 5- $\mathrm{HT}_{2 \mathrm{~B}}$ antagonistic activity of HF was depicted by shift of CCRC of 5-HT towards the right with suppression of the maxima.

The hypertensive mechanism due to chronic administration of DOCA-salt has been well documented. DOCA-salt being a mineralocorticoid causes salt and water retention and contributes to the development of hypertension. Absence of antihypertensive substances normally produced by kidney such as prostaglandins (PGs) may influence the pathogenesis of this type of hypertension. Alteration of central serotonergic level: 5-HT, 5hydroxy indole acetic acid (5-HIAA) and tryptophan increase in certain brain regions have been reported (Dawson et al., 1988). Upregulation of arterial serotonin $1 \mathrm{~B}$ and $2 \mathrm{~B}$ receptors, in DOCA salt and L-NAME hypertensive rats is decreased by $5-\mathrm{HT}_{2 \mathrm{~B}}$ antagonist LY-272015 (Watts et al., 1997; Cohen et al., 1996). Brain reticular activating system (RAS) regulates BP in DOCA-salt hypertensive rats and its mechanism of action is closely related to changes in $\mathrm{Na}^{+}$excretion and vasopressin and the baroreceptor (Bereck et al., 1982).

Fructose induced hypertension model gives clue about the role of dietary changes in hypertension, which has become an important factor of modern life style. The mechanism of fructose-induced hypertension is not clear. Recent studies have shown that a high fructose diet is associated with 
increased BP in rats (Juann et al., 1988; Bunnag et al., 1997; Dimo et al., 2001). Chronic fructose feeding leads to insulin resistance, glucose intolerance, hyperinsulinemia, hyperglycemia and hypertriglyceridemia in a relatively short time in normal rats (Zavaroni et al., 1980; Hwang et al., 1987; Erlich and Rosenthal, 1995). This metabolic change leads to essential hypertension (Rosen et al., 1997). Hyperinsulinemia could activate the sympathetic system, which in turn could elevate the BP (Hwang et al., 1987). An improved response to endothelium dependant vasodilators in fructose fed rats also has been demonstrated (Richey et al., 1998).

The 5- $\mathrm{HT}_{2 \mathrm{~B}}$ receptor, first called atypical 5-HT receptor, as highly sensitive 5-HT receptor in the longitudinal smooth muscle of the rat stomach fundus (Vane, 1957). Arterial smooth muscle from the DOCA-salt hypertensive rat display an increase in sensitivity to 5-HT, although arteries from most models of hypertension show some increase in responsiveness to 5-HT (McGregor et al., 1970; Cumming et al., 1986; Thompson et al., 1987; MacLean et al., 1996; Roson et al.,1997). It has been previously reported that part of this increase in arterial sensitivity to 5-HT is due to a change in the receptor population that mediates contraction to 5-HT under condition of DOCA-salt hypertension. Specifically, Watts and Colleagues (Watts, 1988; Watts et al., 1995, 1996) presented pharmacological and molecular evidence that a $5-\mathrm{HT}_{2 \mathrm{~A}}$ receptor population (ketanserin sensitive) primarily mediates arterial contraction in DOCA-salt hypertension. This "switch" is important because 5 -HT possesses 300 - 1,000 times higher affinity for the $5-\mathrm{HT}_{2 \mathrm{~B}}$ receptor compared with the $5-\mathrm{HT}_{2 \mathrm{~A}}$ receptor (Wainscott et al., 1993, 1996); thus lower concentrations of $5-\mathrm{HT}$ are necessary to activate the $5-\mathrm{HT}_{2 \mathrm{~B}}$ receptor. Moreover, this finding makes important the re-examination of hypertension with new pharmacological tools that block the $5-\mathrm{HT}_{2 \mathrm{~B}}$ receptor, because the serotonergic antagonist most frequently tested has been ketanserin and ketanserin possesses $\sim 1,000$ times lower affinity for the $5-\mathrm{HT}_{2 B}$ receptor compared with the $5-\mathrm{HT}_{2 \mathrm{~A}}$ receptor (Wainscott et al., 1993).

Thus, in conclusion the results of the present study suggest that 5-HT plays an important role in the development of hypertension and the herbal formulation contains ingredients which possess antihypertensive effect partly due to their $5-\mathrm{HT}_{2 \mathrm{~B}}$ receptor antagonism.

\section{ACKNOWLEDGEMENT}

The authors are grateful to Prin. V. M. Aurangabadkar for providing necessary lab facilities and for his continuous support and encouragement.

\section{REFERENCES}

Aeshbaech R, Loliger J, Scott BC, Murcia A, Butters J, Halliwell B, Arouma OI. (1994) Antioxidant activities of thymol, carvacrol, 6-gingerol, zingerone and hydroxytyrosol. Fd. Chem. Toxic. 32, 31-36.

Alam MI, Gomes A. (1998) Viper venom induced inflammation and inhibition of free radical formation by pure compound (2-hydroxy-4 methoxy benzoic acid) isolated and purified from H.indicus root extracts. Toxicon. 36, 207-215.

Badyal DK, Lata H, Dadhich AP. (2003) Animal model of hypertension and effect of drugs. Indian J. Pharmacol. 35, 349-362.

Balaraman R, Hingorani N, Rathod SP. (1993) Studies on the Antihypertensive Effect of Abana in rats. Indian J. Pharmacol. 25, 209-214.

Balaraman R, Dandwal S, Mohan M. (2006) Antihypertensive effect of Trigonella Foenum-greacum seeds in experimentally induced hypertension in rats. Pharm. Biol. 44, 568-575.

Balaraman R, Gulati OD, Bhatt SD, Rathod SP, Hemavati KG. (1989) Cadmium induced hypertension in rats. Pharmacol. 38, 226-234.

Banes AK, Watts SW. (2003) Arterial expression of $5-\mathrm{HT}_{2 \mathrm{~B}}$ and $5-\mathrm{HT}_{1 \mathrm{~B}}$ receptors during development of DOCA-salt hypertension. BMC Pharmacol. 3, 12-19.

Bereck KH, Barron KW, Webb RL, Brody MJ. (1982) Vasopressin CNS interaction in the development of DOCA hypertension. Hypertension 4, 131-137.

Bone K, Gupta. (1997) Traditional uses, chemical 
constituents, antiplatelet, anti inflammatory, cardiovascular and antioxidant properties of ginger. Br. J. Phytotherapy 4, 110-120.

Bunnag P, Hori TM, Ormsby B, Berger ME, Golub SM, Tuck LM. (1997) Impaired in vitro adrenergic responses in diet-induced hypertensive rats. Hypertension Res. 20, 17-21.

Chandra T, Sadique J, Somasundaram, S. (1987) Anti inflammatory activity of E. alba. Fitoterapia 58, 28.

Chopra RN, Chopra IC, Varma BS. (1969) Supplement to Glossary of Indian Medical Plants. CSIR. New Delhi. p.73.

Cohen ML, Schenck KW, Mabry TE, Nelson DL, Audia JE. (1996) LY272015, A potent selective and orally active $5-\mathrm{HT}_{2 \mathrm{~B}}$ receptor antagonist. J. Ser. Res. 3, 131-144.

Cosenzi A, Sacerdote A, Seculin P, Odoni G, Plazzotta N, Bernobich E, Bellini G. (1999) Lacidipine prevents the hypertension and renal cardiac changes induced by high fructose diet in WKY rats. J. Cardiovasc. Pharm. 33, 485-491.

Cummings SA, Groszmann RJ, Kaumann AJ. (1986) Hypertsensitivity of mesenteric veins to 5-hydroxytryptamine and ketanserin-induced reduction of partal pressure in portal hypertensive rats. $\mathrm{Br}$. J. Pharmacol. 89, 501-513.

Dimo T, Azay J, Tan PV, Pellecuer J, Cros G, Bopelet M, Serrano JJ. (2001) Effects of the aqueous and methylene chloride extract of Bidens pilosa leaf on fructose hypertensive rats. J. Ethnopharmacol. 76, 215-221.

Dawson R, Nagamhama S, Oparil S. (1988) Central serotonergic alterations in deoxycorticosterone acetate/ NaCl-induced hypertension. Neuropharmacology 27, 417-426.

Erlich Y, Rosenthal T. (1995) Effect of angiotensinconverting enzyme inhibitors on fructose induced hypertension and hyperinsulinemia in rats. Clin. Exp. Pharmacol. Physiol. 22, S347-S349.

Guerrero MF, Carrona R, Martýna ML, San Romana L, Reguerob MT. (2001) Antihypertensive and vasorelaxant effects of aqueous extract from Croton schiedeanus Schlecht in rats. J. Ethnopharmacol. 75, 33-36.

Gupta SC, Bajaj UK, Sharma VN (1976) Cardiovascular effects of Eclipta alba Hassk. (Bhringaraja). J. Res. Indian Med. 11, 91-93.

Greenberg S, Heitz DC, Long JP. (1973) Testosterone induced depression of adrenergic activity in the perfused canine hind limb. J. Pharmacol. Exp. Ther. 184, 56-66.

Hwang IS, Ho H, Hoffman BB, Reavan GM. (1987) Fructose-induced depression of adrenergic activity in the perfused canine hind limb. Proc. Soc. Exp. Biol. Med. 142, 883-888.

Ibarrol DA, Ibarrol MH, Vera C, Montalbett Y, Ferrob EA. (1996) Hypotensive effect of crude root extract of Solanum sisymbriifolium (Solanaceae) in normoand hypertensive rats. J. Ethnopharmacol. 54, 712.

Inamadar MC, Rajarama Rao MS. (1962) Studies on the pharmacology of T. Chebula. J. Sci. Industr. Res. 21, 345.

Jouad H, Lacaille-Dubois MA, Lyoussi B, Eddouks M. (2001) Effects of the flavonoids extracted from Spergularia purpurea Pers on arterial BP and renal function in normal and hypertensive rats. J. Ethnopharmacol. 76, 159-163.

Juan CC, Fang VS, Hsu YP, Huang YJ Hsia DB, Yu PC, Kwok CF, Ho LT. (1988) Overexpression of vascular endothelin-1 and endothelin-A receptors in a fructose-induced hypertensive rat model. J. Hyp. 12, 1775-1782.

Kim NJ and Hong ND. (1996) Studies on the processing of crude drugs (v) on the constituents and biological activities of glycyrhiza. Korean J. Pharmacog. 27, 196-206.

Maclean MR, Clayton RA. (1996) Templeton AGB and Morecroft I. Br. J. Pharmacol. 119, 277-282.

Mishra M, Shukla YN, Jain SP, Shushil Kumar (1999) Chemistry and pharmacology of some Hibiscus species. J. Med. Aroma. plant Sci. 21, 1169-1186.

McGregor DD, Smirk FH. (1970) Vascular responses to 5-hydroxytryptamine in genetic and renal hypertensive rats. Am. J. Physiol. 219, 687-690.

Nakagawa M, Nasjletti A. (1988) Plasma rennin concentration in Deoxycorticosterone salt hypertension. Hypertension 11, 411-415.

RAO Man-Ren, (2002) Effects of tetrandrine on cardiac and vascular remodeling. Acta Pharmacol. Sinica. 23, 1075-1085.

Richey JM, Si X, Halter JB, Webb RC. (1998) Fructose perfusion in rat mesenteric arteries impairs endothelium-dependant vasodilation. Life Sci. 62, PL55-PL62.

Rosen P, Ohly P, Gleichmann H. (1997) Experimental 
benefit of moxonidine on glucose metabolism and insulin secretion in the fructose -fed rat. J. Hyp. 15, S31-S38.

Shah LP, Patil SP, Patil J. (1997) Observation on clinical evaluation of indigenous herbal drugs in the treatment of mental illness. Indian J. Pharmacol. 29, 347-349.

Sharma R. (2004) Agro techniques of Medicinal plants, Daya Publication House, Delhi, 1-10.

Sreeramamurthy T, Ganga Rao B, Satyanarayana T, Krishna Rao RV. (1993) Hepatoprotective activity of Eclipta alba. Jour. Res. Edu. Indian Med. 2, 41-43.

Srivastava RD, Dwivedi S, Sreenivasan KK, Chandrasekar CN (1991) Cardiovascular effects of Terminalia species of plants. Indian Drugs. 29, 144-149.

Takagi N, Sanashiro. (1996) Health foods containing antioxidative and antiallergy food materials. Jpn. Kokoi Tokkyo Koho. 70, 1000.

Thompson LP, Webb RC. (1987) Vascular responsiveness to serotonin metabolites in mineralocorticoid hypertension. Hypertension 9, 277-281.

Vane JR. (1957) A sensitive method for the assay of 5-hydroxytryptamine. Br. J. Pharmacol. 12, 344-349.

Vogel GH. (2002) Drug Discovery and Evaluation: pharmacological Assays. pp.175. Second edition, Springer publication, New York.

Wainscott DB, Lucaites VL, Kursar JD, Baeez M,
Nelson DL. (1996) Pharmacological characterization of the human 5-Hydroxytrptamine ${ }_{2 B}$ receptor: Evidence for species differences. J. pharmacol. Exp. Ther. 276, 720-727.

Wainscott D, Cohen ML, Schenck KW, Audia JE, Nissen JS, Baez M, Nelson DL. (1993) Pharmacological characterization of newly cloned rat 5-hydroxytryptamine $_{2 \mathrm{~F}}$ receptor. Mol. Pharmacol. 43, 419-426.

Watts SW. (1988) The development of enhanced arterial serotonergic hyperresponsiveness in mineralocorticoid hypertension. J. Hypertens. 16, 811-822.

Watts SW, Gilbert L, Webb RC. (1995) The 5Hydroxytrptamine $_{2 \mathrm{~B}}$ receptor mediates contraction in the mesenteric artery of mineralocorticoid hypertensive rats. Hypertension 26, 1056-1059.

Watts SW, Baez M, Webb RC. (1996) 5- $\mathrm{HT}_{2 \mathrm{~B}}$ receptor and 5-HT receptor signal transduction in mesenteric artery from mineralocorticosterone acetate-salt hypertension. J. Pharmacol. Exp. Ther. 277, 1103-1113.

Watts SW. (1997) The 5- $\mathrm{HT}_{2 \mathrm{~B}}$ receptor LY272015 inhibits 5-HT-induced contraction in the aorta of mineralocorticoid-salt hypertensive rats. J. Ser. Res. 4, 197-206.

Zavaroni I, Sander S, Scott S, Reaven GM. (1980) Effect of fructose feeding on insulin secretion and action in the rat. Metabolism 29, 970-973. 